\title{
Gas Chromatography - Mass Spectrometry Analysis and In vitro Antioxidant Activity of the Ethanolic Extract of the Leaves of Tabernaemontana divaricata
}

\author{
Muniyandi Anbukkarasi ${ }^{1}$, Philip A Thomas², Mahalingam Sundararajan ${ }^{1}$, Pitchairaj Geraldine ${ }^{1 *}$ \\ 'Department of Animal Science, School of Life Sciences, Bharathidasan University, Tiruchirappalli- 620 024, Tamil Nadu, INDIA. \\ 2Department of Ocular Microbiology, Institute of Ophthalmology, Joseph Eye Hospital, Tiruchirappalli- 620 001, Tamil Nadu, INDIA.
}

\begin{abstract}
Objective: To identify phytoconstituents present in an ethanolic extract of the leaves of Tabernaemontana divaricata and to evaluate its in-vitro antioxidant potential. Methods: The extract was subjected to gas chromatography-mass spectrometry analysis to identify phytoconstituents, and screened for hydroxyl, superoxide and 1, 1-diphenyl-2-picrylhydrazyl (DPPH) radical scavenging activity, reducing power and metal-chelating activity as a measure of potential antioxidant activity. Results: GC-MS analysis of the extract revealed the presence of 96 phytoconstituents, of which 17 are reported to be bioactive and 11 of these to possess antioxidant potential. When tested in-vitro, the extract exhibited the most potent radical-scavenging activity at a maximum concentration of $10 \mathrm{mg} / \mathrm{ml}$, scavenging effects of $64 \%, 67 \%$ and $69 \%$ and corresponding half maximal inhibitory concentration $\left({ } C_{50}\right)$ values of $6.7 \mathrm{mg} / \mathrm{ml}, 6.8 \mathrm{mg} / \mathrm{ml}$ and $6.2 \mathrm{mg} / \mathrm{ml}$ on hydroxyl, superoxide and DPPH radicals, respectively. Ascorbic acid used as a standard $(10 \mathrm{mg} / \mathrm{ml})$ showed scavenging effects of $73 \%, 73 \%$ and $75 \%$ and corresponding $I \mathrm{I}_{50}$ values of $5.3 \mathrm{mg} / \mathrm{ml}, 5.8 \mathrm{mg} / \mathrm{ml}$ and $5.2 \mathrm{mg} / \mathrm{ml}$, respectively, on hydroxyl, superoxide and DPPH radicals. At $10 \mathrm{mg} / \mathrm{ml}$, the extract and an ethylenediaminetetraacetic acid standard
\end{abstract}

exhibited $68 \%$ and $78 \%$, respectively, chelation of ferrous ions; at the same concentration, the reducing power of the extract and that of a butylated hydroxytoluene standard was found to be 3.855 and 4.308 , respectively. Conclusion: These observations strongly suggest that the ethanolic extract of $T$. divaricata leaves has potent in-vitro antioxidant activity and thereby could act as a possible therapeutic agent for oxidative stressinduced pathological states.

Key words: Tabernaemontana divaricata, GC-MS analysis, Phytoconstituents, Antioxidant activity, Reducing power, Metal chelating activity.

Corresponding author: Dr. P.Geraldine, Department of Animal Science, School of Life Sciences, Bharathidasan University, Tiruchirappalli-620 024, Tamil Nadu, INDIA.

Tel: Phone: +91-431-2407040, Fax: +91-431-2414969

Email: gerryarchup@yahoo.co.in

DOI : 10.5530/pj.2016.5.7

\section{INTRODUCTION}

An antioxidant is a compound that inhibits or retards the oxidation of substrates even if it is present in a significantly lower concentration than that of the oxidised substrate. ${ }^{1}$ A possible mechanism of antioxidant activity is scavenging of reactive oxygen species (ROS); others include the prevention of ROS formation by binding of metal or inhibition of enzyme. ROS may initiate several human degenerative diseases, and antioxidants may exert defensive and therapeutic effects on many metabolic disorders. ${ }^{2}$ Interestingly, clinical and epidemiologic studies in some cases have pointed out that antioxidant nutrients may be effective in disease prevention. ${ }^{3}$ However, the use of synthetic antioxidative agents, such as butylated hydroxyanisole (BHA), butylated hydroxytoluene (BHT), propylgallate (PG), and tertiary-butyl hydroxytoluene is restricted as they are suspected to be carcinogenic despite exhibiting potent free radical-scavenging effects. ${ }^{4-6}$ Therefore, there is an increasing interest in the extraction of antioxidants from natural sources by various techniques $^{7-9}$ as well as identification of compounds with antioxidant activity to replace synthetic food additives. ${ }^{10-11}$

The developed world is witnessing increasing interest in complementary and alternative medicine (CAM), particularly herbal remedies. Herbal medicines include herbs, herbal materials, herbal preparations, and finished herbal products that contain parts of plants or other plant materials as active ingredients. ${ }^{12}$ Medicinal plants, unlike pharmacological drugs, commonly contain several chemicals working together catalytically and synergistically since they possess different phytochemicals, that is, secondary metabolites, that produce a combined effect that surpasses the total activity of the individual constituents. ${ }^{13-14}$ So also, due to synergistic effects, medicinal plants are reported to be more biologically active than their purified constituents. ${ }^{15}$

Tabernaemontana divaricata ( $T$. divaricata) is one such medicinallyimportant plant belonging to the family Apocynaceae. ${ }^{16}$ It is a glabrous, evergreen, dichotomously-branched shrub, locally known as 'nandiyavattom' (synonyms: Tabernaemontana coronaria, Ervatamia coronaria, Ervatamia divaricata and Ervatamia microphylla) and is believed to exhibit antioxidant, anti-infectious, anti-tumorogenic, anti-bacterial and analgesic properties. ${ }^{17-18}$ Jain et al. ${ }^{19}$ also reported that aqueous and ethanolic extracts of $T$. divaricata leaves were able to scavenge superoxide radicals in-vitro. Hence, in the present investigation, an attempt was made to identify bioactive constituents of the leaves of $T$. divaricata and to elucidate various antioxidant characteristics such as potential radicalscavenging and metal-chelating activities and reducing power of the leaf extract.

\section{MATERIALS AND METHODS}

\section{Preparation of an ethanolic extract of $T$. divaricata leaves}

The leaves of T. divaricata plant were collected from within the Bharathidasan University campus, Tiruchirappalli, Tamilnadu, India. The plant was identified by the Rapinat Herbarium and Centre for Molecular Systematics, St.Joseph's College, Tiruchirappalli, India. The voucher specimen (No: KV 001) has been preserved in the Department of Animal Science, Bharathidasan University, Tiruchirappalli, India.

The leaves (fresh and disease-free) were shade-dried and finely powdered. Thirty grams of the powder were extracted with $300 \mathrm{ml}$ of 
95\% ethanol using a Soxhlet apparatus. The solvent was evaporated under reduced pressure at $55-60^{\circ} \mathrm{C}$ and dried in a vacuum. The residue was filtered and concentrated to a dry mass by vacuum distillation. This dried ethanolic extract of $T$. divaricata was used for further analyses.

\section{GC-MS analysis of the T. divaricata extract}

The ethanolic extract of $T$. divaricata underwent gas chromatography-mass spectrometry (GC-MS) analysis (GC-MS - QP-2010 Plus, Shimadzu, Tokyo, Japan) with the thermal desorption (TD) system 20. Experimental conditions of the GC-MS system were as follows: Trace- 5 mass spectrometry capillary standard non-polar column, dimension: 30 meters; internal diameter: $0.25 \mathrm{~mm}$; film thickness: $0.25 \mu \mathrm{m}$. The flow rate of the mobile phase (carrier gas: helium) was set at $1.2 \mathrm{ml} / \mathrm{min}$. In the gas chromatography phase, the temperature programme (oven temperature) was $80^{\circ} \mathrm{C}$, which was raised to $250^{\circ} \mathrm{C}$ at $10^{\circ} \mathrm{C} / \mathrm{min}$, and the injection volume was $1 \mu \mathrm{l}$. Samples dissolved in chloroform were run fully at a range of 50-650 mass-to-charge ratio $(\mathrm{m} / \mathrm{z})$ and the results were compared by using the Wiley Spectral Library Search Programme (http:// www.sisweb.com/software/ms/wiley-search.html).

\section{Determination of putative in vitro antioxidant activities of the ethanolic extract of $T$. divaricata leaves}

\section{Determination of possible hydroxyl radical- scavenging activity in the T. divaricata extract}

The hydroxyl radical $\left(\mathrm{OH}^{-}\right)$-scavenging capacity of the $T$. divaricata extract was measured according to the modified method of Halliwell et al. ${ }^{20}$ Stock solutions of ethylenediamine tetraacetic acid (EDTA, $1 \mathrm{mM}$ ), ferric chloride $\left(\mathrm{FeCl}_{3} 10 \mathrm{mM}\right)$, ascorbic acid $(1 \mathrm{mM})$, hydrogen peroxide $\left(\mathrm{H}_{2} \mathrm{O}_{2}, 10 \mathrm{mM}\right)$ and deoxyribose $(10 \mathrm{mM})$ were prepared in distilled and deionized water.

The assay was performed by adding $0.1 \mathrm{ml}$ of EDTA, $0.01 \mathrm{ml}$ of $\mathrm{FeCl}_{3}$ $0.1 \mathrm{ml}$ of $\mathrm{H}_{2} \mathrm{O}_{2}, 0.36 \mathrm{ml}$ of deoxyribose, $1.0 \mathrm{ml}$ of the extract (2 to $10 \mathrm{mg}$ ) $\mathrm{ml}$ ) dissolved in distilled water, $0.33 \mathrm{ml}$ of phosphate buffer $(50 \mathrm{mM}, \mathrm{pH}$ 7.4 ) and $0.1 \mathrm{ml}$ of ascorbic acid, in sequence. This mixture was then incubated at $37^{\circ} \mathrm{C}$ for 1 hour. A $1.0 \mathrm{ml}$ portion of the incubated mixture was mixed with $1.0 \mathrm{ml}$ of $10 \%$ trichloroacetic acid (TCA) and $1.0 \mathrm{ml}$ of $0.5 \%$ thiobarbituric acid (TBA) [in $0.025 \mathrm{M}$ sodium hydroxide $(\mathrm{NaOH})$ containing $0.025 \%$ butylated hydroxyl aniline (BHA)] to develop the pink chromogen which was measured at $532 \mathrm{~nm}$. L-ascorbic acid was used as a standard. The $\mathrm{OH}^{-}$-scavenging activity of the extract was reported as \% inhibition of deoxyribose degradation and was calculated as

$$
\mathrm{OH}^{-} \text {Scavenged }(\%)=\left(\mathrm{A}_{\text {cont }}-\mathrm{A}_{\text {test }}\right) / \mathrm{A}_{\text {cont }} \times 100
$$

where $A_{\text {cont }}$ is the absorbance of the control reaction and $A_{\text {test }}$ is the absorbance of the mixture containing the extract or the absorbance of a standard solution.

\section{Determination of putative superoxide radical- scavenging activity in the $T$. divaricata extract}

The superoxide anion radical-scavenging capacity of the $T$. divaricata extract was measured essentially as described by Liu et al..$^{21}$ using a minor modification proposed by Rajeshwar et al. ${ }^{22}$ The principle of this method is that superoxide radicals are generated in phenazine methosulphate (PMS) - nicotinamide adenine dinucleotide (NADH) systems by oxidation of NADH and assayed by the reduction of nitroblue tetrazolium (NBT). In this experiment, the superoxide radicals were generated in $3.0 \mathrm{ml}$ of Tris- $\mathrm{HCl}$ buffer $(16 \mathrm{mM}, \mathrm{pH} 8.0)$ containing $1.0 \mathrm{ml}$ of NBT $(50 \mu \mathrm{M})$ solution, $1.0 \mathrm{ml}$ of $\mathrm{NADH}(78 \mu \mathrm{M})$ solution and samples of the extracts
( 2 to $10 \mathrm{mg} / \mathrm{ml}$ ) in water. The reaction was initiated by adding $1.0 \mathrm{ml}$ of PMS $(10 \mu \mathrm{M})$ solution to the mixture. The reaction mixture was incubated at $100^{\circ} \mathrm{C}$ for 5 minutes and the absorbance was measured at 560 $\mathrm{nm}$ against a blank. L-ascorbic acid was used as a standard. Decreased absorbance of the reaction mixture indicated increased superoxide anion-scavenging activity. The percentage (\%) inhibition of superoxide anion generation was calculated using the same formula that was used to calculate the $\mathrm{OH}^{-}$-scavenging activity.

\section{Determination of possible 1, 1-diphenyl-2- picrylhydrazyl (DPPH) radical-scavenging activity in the T. divaricata extract}

The potential of the $T$. divaricata extract to scavenge the stable radical DPPH (1, 1-diphenyl-2-picrylhydrazyl) was measured by the method described by Kikuzaki and Nakatani, ${ }^{23}$ with slight modifications. In this experiment, $1.0 \mathrm{ml}$ of $0.1 \mathrm{mM} \mathrm{DPPH}$ prepared in methanol was mixed with $1.0 \mathrm{ml}$ of the extract (ranging from 2 to $10 \mathrm{mg} / \mathrm{ml}$ ). The reaction mixture was shaken vigorously and left in the dark at room temperature for 30 minutes. The absorbance was then measured at $517 \mathrm{~nm}$ against a blank; L-ascorbic acid was used as a standard. Decreased absorbance of the reaction mixture indicated higher free radical-scavenging activity. $\mathrm{DPPH}$ radical-scavenging activity was calculated using the same formula as that used to calculate the $\mathrm{OH}^{-}$-scavenging activity.

\section{Determination of putative reducing power in the $T$. divaricata extract}

The putative reducing power of the T. divaricata extract was determined by the method of Oyaizu. ${ }^{24}$ Various concentrations of the extract ( 2 to $10 \mathrm{mg} / \mathrm{ml}$ ) in deionized water were mixed with phosphate buffer $(2.5 \mathrm{ml}, 0.2 \mathrm{M}, \mathrm{pH} 6.6)$ and $1 \%$ potassium ferricyanide $(2.5 \mathrm{ml})$. The mixture was incubated at $50^{\circ} \mathrm{C}$ for 20 minutes. Aliquots of TCA $(2.5$ $\mathrm{ml}, 10 \%)$ were added to the mixture, which was then centrifuged at $1036 x$ for 10 minutes. The upper layer of the solution $(2.5 \mathrm{ml})$ was mixed with distilled water $(2.5 \mathrm{ml})$ and a freshly-prepared $\mathrm{FeCl}_{3}$ solution $(0.5 \mathrm{ml}, 0.1 \%)$. The absorbance was measured at $700 \mathrm{~nm}$. Increased absorbance of the reaction mixture was interpreted as an increase in reducing power. The standard, BHT, was also processed by the same procedures.

\section{Determination of possible metal-chelating activity in the T. divaricata extract}

The potential of the extract of T. divaricata to chelate ferrous ions was measured by the method of Dinis et al. ${ }^{25}$ Briefly, the extract (2 to $10 \mathrm{mg} / \mathrm{ml}$ ) was added to a solution of $2 \mathrm{mM} \mathrm{FeCl}_{2}(0.05 \mathrm{ml})$. The reaction was initiated by the addition of $5 \mathrm{mM}$ ferrozine $(0.2 \mathrm{ml})$, and the mixture was then shaken vigorously and left to stand at room temperature for 10 minutes. The absorbance of the solution was measured spectrophotometrically at $562 \mathrm{~nm}$. EDTA was used as a standard. The percentage (\%) inhibition of ferrozine- $\mathrm{Fe}^{2+}$ complex formation was calculated as

$$
\left[\left(\mathrm{A}_{0-} \mathrm{A}_{1}\right) / \mathrm{A}_{0}\right] \times 100
$$

where $A_{0}$ was the absorbance of the control, and $A_{1}$ was the absorbance of the mixture containing the extract or the absorbance of a standard solution.

\section{Statistical Analysis}

Results are presented as mean \pm standard deviation of three measurements. Statistical analysis of the data was performed by Student' $t$ ' test using SPSS (Statistical Package for Social Sciences) software package for Windows (version 16.0; IBM Corp., Armonk, NY, USA). P values $<0.05$ were regarded as significant. 


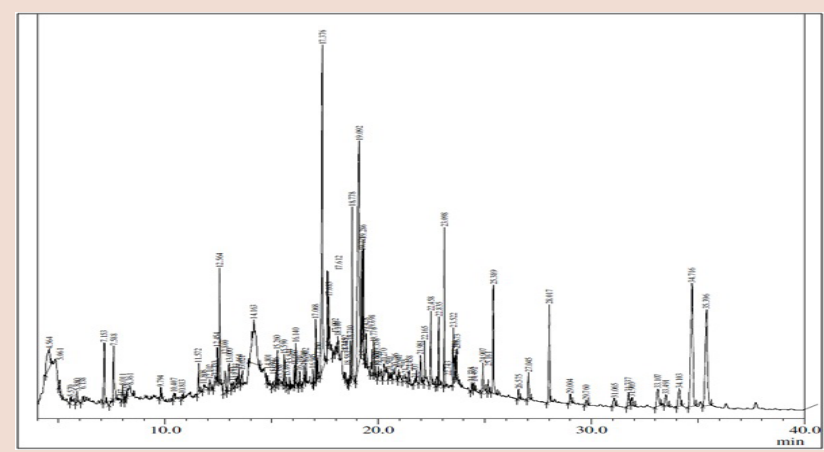

Figure 1: Gas chromatography-mass spectrometry chromatogram of an ethanolic extract of Tabernaemontana divaricata leaves.

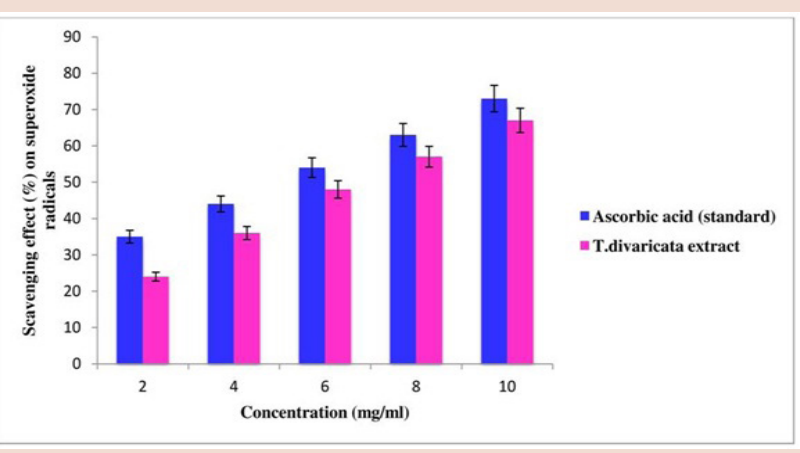

Figure 3: Scavenging effect of an ethanolic extract of Tabernaemontana divaricata leaves on superoxide radicals compared to that of an ascorbic acid standard.

\section{RESULTS}

\section{GC-MS analysis of the ethanolic extract of $T$. divaricata leaves}

The chromatogram generated by GC-MS analysis (Figure 1) of the extract revealed the presence of 96 compounds, of which 17 are reported tobebioactive(Table1 andTable2) whentestedfromothersources. Themajor bioactive constituents in the leaf extract of T. divaricata, based on area percentage, included n-hexadecanoic acid (11.18\%), phytol (2.97\%), octadecanoic acid (1.76\%), 4H-pyran-4-one, 2,3-dihydro-6 methyl (1.60\%), 9,12,15-octadecatrienoic acid ethyl ester (z,z,z) $(1.47 \%)$, and hexadecanoic acid ethyl ester (1.28\%) (Table 2). These 17 compounds were detected at different retention times (5.880 to 33.107 minutes) and the area percentage varied from $0.17 \%$ to $11.18 \%$ (Table 2). Eleven of the 17 compounds have been reported to possess antioxidant properties (Table 1).

\section{In vitro antioxidant activity of the extract of $T$. divaricata leaves}

\section{Scavenging effect of the T. divaricata extract on hydroxyl radicals}

In the present study, the T. divaricata leaf extract and the ascorbic acid standard were found to inhibit $\mathrm{OH}^{-}$-mediated deoxyribose degradation in the reaction mixture. The $\mathrm{OH}^{-}$-scavenging effect of the $T$. divaricata

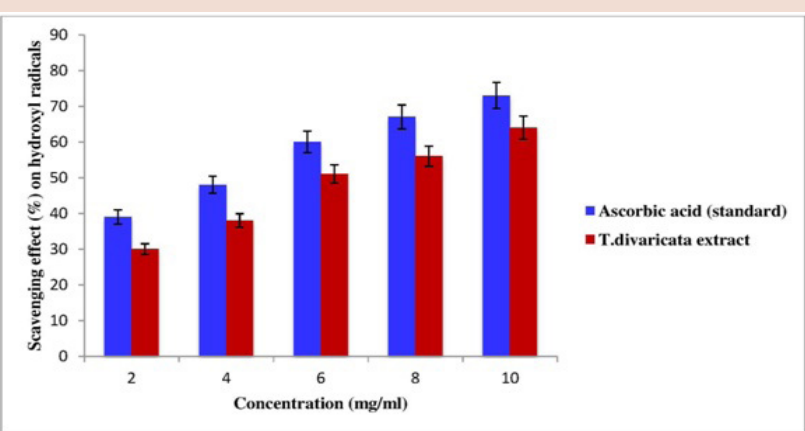

Figure 2: Scavenging effect of an ethanolic extract of Tabernaemontana divaricata leaves on hydroxyl radicals compared to that of an ascorbic acid standard.

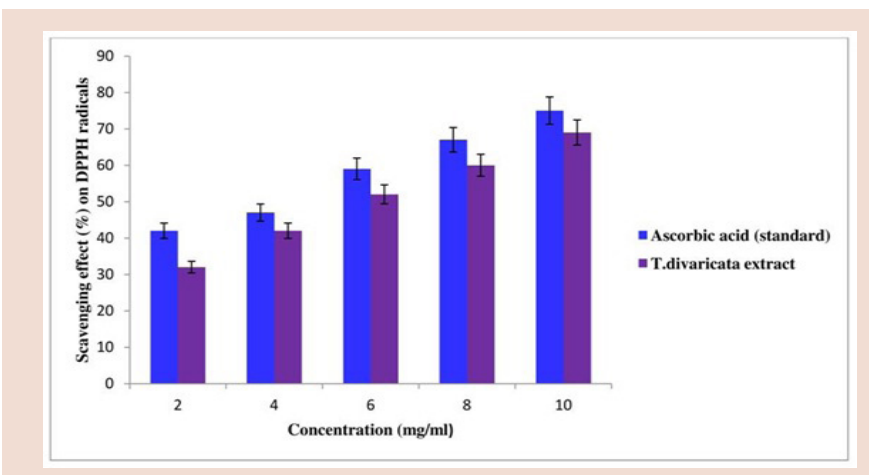

Figure 4: Scavenging effect of an ethanolic extract of Tabernaemontana divaricata leaves on 1,1-dipheny1-2-picrylhydrazyl (DPPH) free radicals compared to that of an ascorbic acid standard.

extract $(10 \mathrm{mg} / \mathrm{ml})$ was $64 \%$ while that of ascorbic acid $(10 \mathrm{mg} / \mathrm{ml})$ was $73 \%$; this difference was statistically significant $(p<0.05)$ (Figure 2$)$. The $\mathrm{IC}_{50}$ values were found to be $6.7 \mathrm{mg} / \mathrm{ml}$ and $5.3 \mathrm{mg} / \mathrm{ml}$, respectively, for the extract of $T$. divaricata and for ascorbic acid.

\section{Scavenging effect of the T. divaricata extract on superoxide anion radicals}

The \% inhibition of superoxide radical generation by the ethanolic extract of $T$. divaricata leaves $(10 \mathrm{mg} / \mathrm{ml})$ and that of the standard ascorbic acid solution $(10 \mathrm{mg} / \mathrm{ml})$ were found to be $67 \%$ and $73 \%$, respectively (Figure 1-6), as measured by the riboflavin-light system in-vitro. The $\mathrm{IC}_{50}$ values were found to be $6.8 \mathrm{mg} / \mathrm{ml}$ and $5.8 \mathrm{mg} / \mathrm{ml}$, respectively, for the extract of T. divaricata and for ascorbic acid.

\section{Scavenging effect of the T. divaricata extract on DPPH radicals}

The $T$. divaricata leaf extract exhibited significant DPPH radicalscavenging effects with increasing concentrations $(2-10 \mathrm{mg} / \mathrm{ml})$, when compared with that of ascorbic acid (Figure 4 ). The \% scavenging of $\mathrm{DPPH}$ by the $T$. divaricata extract $(10 \mathrm{mg} / \mathrm{ml})$ and that of ascorbic acid $\left(10 \mathrm{mg} / \mathrm{ml}\right.$ ) was found to be $69 \%$ and $75 \%$, respectively, while the $\mathrm{IC}_{50}$ values were found to be 6.2 and $5.2 \mathrm{mg} / \mathrm{ml}$, respectively.

\section{Reducing power of the T. divaricata extract}

The reducing power of the ethanolic extract of $T$. divaricata leaves was found to steadily increase in direct proportion to increasing concentra- 


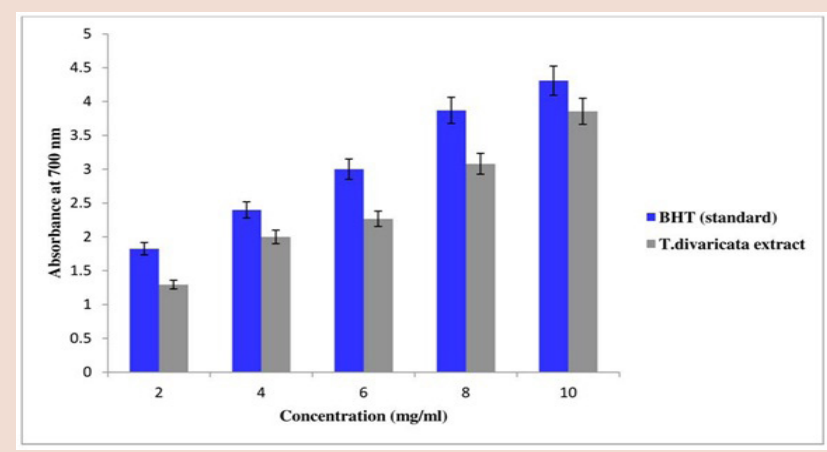

Figure 5: Reducing power of an ethanolic extract of Tabernaemontana divaricata leaves compared to that of a butylated hydroxytoluene (BHT) standard.

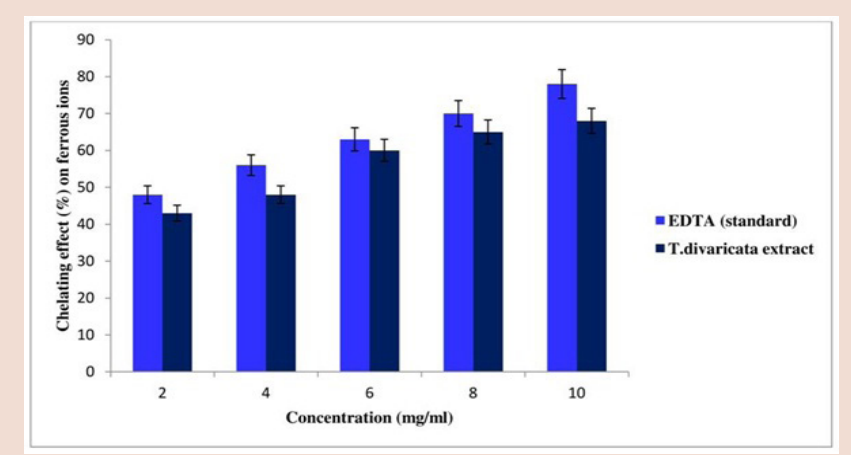

Figure 6: Chelating effect of an ethanolic extract of Tabernaemontana divaricata leaves on ferrous ions compared to that of an ethylenediaminetetraacetic acid (EDTA) standard.

Table 1: Biological activities reported for the phytoconstituents that were detected in the present study by screening of the extract of Tabernaemontana divaricata leaves

\begin{tabular}{|c|c|c|}
\hline Phytoconstituent & Bio-activity & Reference \\
\hline 2-Pyrrolidinone & Antioxidant \& Anticancerous & [33] \\
\hline $\begin{array}{c}\text { 4H-Pyran-4-one,2,3-dihydro- } \\
\text { 6methyl- }\end{array}$ & $\begin{array}{c}\text { Antiproliferative, Antimicrobial \& } \\
\text { Anti-inflammatory }\end{array}$ & {$[30,58]$} \\
\hline Retinol, acetate & Antioxidant & [34] \\
\hline Tetradecanoic acid & Antioxidant \& Nematicidal & [31] \\
\hline $\begin{array}{l}\text { 3,7,11,15-Tetramethyl-2- } \\
\text { hexadecan-1-ol }\end{array}$ & $\begin{array}{l}\text { Antimicrobial, Anti-inflammatory, } \\
\text { Antidiuretic \& Anticancerous }\end{array}$ & {$[31]$} \\
\hline Hexadecanoic acid, methyl ester & Antioxidant, Hypocholesterolemic & {$[31]$} \\
\hline n-Hexadecanoic acid & $\begin{array}{c}\text { Antioxidant, } \\
\text { Hypocholesterolemic, } \\
\text { Antiandrogenic and Hemolytic }\end{array}$ & {$[27-28]$} \\
\hline Hexadecanoic acid, ethyl ester & Antioxidant, Hypocholesterolemic & {$[30]$} \\
\hline Phytol & $\begin{array}{l}\text { Antioxidant, Antimicrobial, } \\
\text { Anticancerous \& Anti- } \\
\text { inflammatory }\end{array}$ & [28-29] \\
\hline Octadecanoic acid & Antimicrobial & {$[31]$} \\
\hline $\begin{array}{l}\text { 9,12,15-Octadecatrienoic acid, } \\
\text { ethyl ester, }(\mathrm{Z}, \mathrm{Z}, \mathrm{Z}) \text { - }\end{array}$ & $\begin{array}{l}\text { Antioxidant, Antimicrobial } \\
\text { Anticancerous \& } \\
\text { Hypocholesterolemic }\end{array}$ & [28] \\
\hline 9,12-Octadecadienoic acid (Z,Z)- & Antioxidant & {$[32]$} \\
\hline $\begin{array}{l}\text { 2,6,10-Trimethyl,14-ethylene-14- } \\
\text { pentadecane }\end{array}$ & Antiproliferative & [59] \\
\hline Vitamin E & $\begin{array}{c}\text { Antioxidant, Anti-inflammatory, } \\
\text { Antitumorogenic, Antileukemic, } \\
\text { Anticoronary, Antidiabetic, } \\
\text { Antiulcerogenic \& Antidermatitic }\end{array}$ & {$[28,31]$} \\
\hline Ergost-5-en-3-ol, (3.Beta.,24R)- & $\begin{array}{l}\text { Antimicrobial \& Anti- } \\
\text { inflammatory }\end{array}$ & {$[31]$} \\
\hline Stigmaestrol & $\begin{array}{c}\text { Antimicrobial, Anti-inflammatory, } \\
\text { Anticancerous, Anti-arthritic \& } \\
\text { anti-asthmatic }\end{array}$ & {$[58]$} \\
\hline Stigmast-5-en-3-ol,(B.Beta)- & $\begin{array}{c}\text { Antioxidant, Antimicrobial \& } \\
\text { Anti-inflammatory }\end{array}$ & {$[31]$} \\
\hline
\end{tabular}




\section{Table 2: Retention times and area percentages of phytoconstituents detected by} gas chromatography - mass spectrometry analysis

\begin{tabular}{ccc}
\hline Phytoconstituent & $\begin{array}{c}\text { Retention Time } \\
\text { (minutes) }\end{array}$ & Area (\%) \\
\hline 2-Pyrrolidinone & 5.880 & 0.38 \\
Retinol, acetate & 7.153 & 1.60 \\
Tetradecanoic acid & 14.801 & 0.17 \\
3,7,11,15-Tetramethyl-2-hexadecan-1-ol & 15.260 & 0.66 \\
Hexadecanoic acid, methyl ester & 16.509 & 0.26 \\
n-Hexadecanoic acid & 16.945 & 0.23 \\
Hexadecanoic acid, ethyl ester & 17.376 & 11.18 \\
Phytol & 17.612 & 1.28 \\
Octadecanoic acid & 18.778 & 2.97 \\
Stigmast-5-en-3-ol,(B.Beta)- & 19.221 & 1.76 \\
9,12,15-Octadecatrienoic acid, ethyl ester, & 19.286 & 1.47 \\
(Z,Z,Z)- & 19.428 & 0.83 \\
9,12-Octadecadienoic acid (Z,Z)- & 19.698 & 0.60 \\
2,6,10-Trimethyl,14-ethylene-14- \\
pentadecane \\
Vitamin E
\end{tabular}

tions of the extract (Figure 5). At a $10 \mathrm{mg} / \mathrm{ml}$ concentration, the reducing power of the extract and that of BHT was found to be 3.855 and 4.308, respectively; this difference was statistically significant $(p<0.05)$.

\section{Metal-chelating activity of the T. divaricata extract}

The iron-binding capacity of the T. divaricata leaf extract was compared to that of a known metal chelator, namely EDTA. The chelating effect of the extract and that of EDTA on ferrous ions was found to increase with increasing concentrations (Figure 6). The extract $(10 \mathrm{mg} / \mathrm{ml})$ and EDTA $(10 \mathrm{mg} / \mathrm{ml})$ exhibited chelating effects of $68 \%$ and $78 \%$, respectively (Figure 6). 50\% chelation of ferrous ions was achieved by the extract and by EDTA in concentrations of $5.4 \mathrm{mg} / \mathrm{ml}$ and $4.6 \mathrm{mg} / \mathrm{ml}$, respectively.

\section{DISCUSSION}

T. divaricata, which is used in Chinese, ayurvedic and Thai traditional medicine, has been reported to exhibit diverse medicinal properties. ${ }^{18,26}$ In the current investigation, an ethanolic extract of $T$. divaricata leaves was screened to detect phytochemical constituents and putative antioxidant components. GC-MS analysis of the extract (Table 2) revealed the presence of 11 key compounds, which have previously been reported to possess antioxidant properties (Table 1). The major constituent detected in the extract of $T$. divaricata, namely n-hexadecanoic acid (area percentage $11.18 \%$ ) (Table 2), has also been reported in an ethanolic extract of Eugenia flocossa leaves ${ }^{27}$ and in a methanolic extract of Vitex negundo leaves ${ }^{28}$ to possess antioxidant, anti-androgenic and hypocholesterolemic properties. Phytol (2.97\%), yet another major constituent
(Table 2), has been reported to possess antioxidant properties and to reduce free-radical generation in an in-vitro experimental system. ${ }^{29}$ Kumar et al. ${ }^{28}$ have also reported that a methanolic extract of Vitex negundo, which was found to have phytol as one of the major constituents, possessed antimicrobial, anti-inflammatory and anti-cancerous properties.

The third major constituent detected in the T. divaricata extract, namely 9, 12, 15-octadecatrienoic acid (Z, Z, Z)-(area percentage 1.47\%) (Table 2), is a linolenic acid; it has been reported to exhibit antioxidant activity in the methanolic extract of Vitex negundo leaves. ${ }^{28}$ The phytoconstituent, hexadecanoic acid ethyl ester (1.28\%) (Table 2), has been reported to possess antioxidant potential in an ethanolic extract of Mussaenda frondosa. ${ }^{30}$ Stigmast 5-en-3-ol (0.99\%) and tetradecanoic acid (0.66\%), detected in the extract of $T$. divaricata in the current study (Table 2), are also reported to occur in a methanolic extract of Aegle marmelos and to exhibit antimicrobial, anti-inflammatory, antiarthritic, anti-fungal and anti-cancerous properties. ${ }^{31}$ Minor components identified in the ethanolic extract of $T$. divaricata leaves in the present study (Table 2) have also been reported to exhibit antioxidant potential. These include: 9, 12-octadecadienoic acid (Z,Z)- (0.83\%), a conjugated linoleic acid reported to occur in an ethanolic extract of Phragmytes vallatoria leaves; ${ }^{32} 2$-pyrrolidinone $(0.38 \%)$, reported in Brassica oleraceae var. capitata; ${ }^{33}$ Vitamin-E (0.32\%), a potential antioxidant that protects the cell against free radicals; ${ }^{28,31}$ hexadecanoic acid methyl ester $(0.23 \%)$, that has been detected in the methanolic fraction of Aegle marmelos ${ }^{31}$ and a well-reported antioxidant compound, retinol $(0.17 \%)$, that inhibits lipid peroxidation. ${ }^{34}$ Thus, $11 \%$ 
of the phytoconstituents identified in the ethanolic extract of $T$. divaricata leaves in the current study have previously been reported to exhibit antioxidant activity. Hence, we hypothesize that these phytoconstituents may contribute to potential antioxidant activity of the extract of $T$. divaricata leaves. To validate this hypothesis, we tested the T. divaricata leaf extract for hydroxyl, superoxide, and DPPH radical-scavenging activity, reducing power and metal-chelating activity.

Hydroxyl radicals can be formed by the Fenton reaction in the presence of reduced transition metals (such as $\mathrm{Fe}^{2+}$ ) and $\mathrm{H}_{2} \mathrm{O}_{2}$, which is known to be the most reactive of all the reduced forms of dioxygen and is thought to initiate cell damage in-vivo. ${ }^{35}$ The potential of an ethanolic extract of T. divaricata leaves to inhibit $\mathrm{OH}^{-}$-mediated deoxyribose damage was assessed by means of an iron (II)-dependent DNA damage assay in the current study. The extract of $T$. divaricata was found to exhibit maximum $\mathrm{OH}^{-}$radical-scavenging activity at a concentration of $10 \mathrm{mg} / \mathrm{ml}$; moreover, the capacity to scavenge $\mathrm{OH}^{-}$radicals increased with increasing concentrations of the extract and of ascorbic acid (Figure 2). Similar $\mathrm{OH}^{-}$-scavenging activity has been reported in several other plant extracts, including Stevia rebaudiana, ${ }^{36}$ Agaricus bisporus, ${ }^{37}$ and Greek oregano. ${ }^{38}$

The superoxide radical $\left(\mathrm{O}_{2}{ }^{-}\right)$is known to be very harmful to cellular components since it is a precursor of ROS. ${ }^{39}$ Photochemical reduction of flavin generates $\mathrm{O}_{2}$, which can reduce NBT, resulting in the formation of blue formazan. ${ }^{40}$ In the present study, the extract of T. divaricata was found to be a notable scavenger of $\mathrm{O}_{2}^{-}$radicals generated in the riboflavin-NBT light system. In a concentration of $10 \mathrm{mg} / \mathrm{ml}$, the extract inhibited the formation of blue formazan at a percentage inhibition of $67 \%$; moreover, the percentage of scavenging $\mathrm{O}_{2}^{-}\left(\mathrm{O}_{2}^{-}\right.$being scavenged leading to inhibition of blue formazan formation) increased with increasing concentrations of the extract and of ascorbic acid (Figure 3). Ascorbic acid, a natural antioxidant, was used as a positive control for comparison. Interestingly, the $\mathrm{O}_{2}{ }^{-}$-scavenging potential of the extract of T. divaricata has also been reported earlier by Jain et al. ${ }^{19}$ The ethanolic extract of Caesalpinia bonducella seeds has been reported to possess similar $\mathrm{O}_{2}{ }^{-}$-scavenging effects. ${ }^{41}$

The DPPH radical is considered to be a model for a lipophilic radical. A chain of lipophilic radicals is initiated by lipid auto oxidation. DPPH is a stable free radical at room temperature and accepts an electron or hydrogen radical to become a stable diamagnetic molecule. ${ }^{42}$ In the $\mathrm{DPPH}$ assay, antioxidants are able to reduce the stable DPPH radical to the non-radical form DPPH-H. When the odd electrons are paired off in the presence of a free radical-scavenger, the absorption is reduced and the color of the DPPH solution changes from purple to yellow. Measurement of the degree of reduction in absorbance at $517 \mathrm{~nm}$ suggests the radical-scavenging potential of a compound. ${ }^{43}$ In the present study, the DPPH radical-scavenging capacity of the extract of $T$. divaricata leaves was found to increase in a dose-dependent manner, as did that of ascorbic acid, although it was significantly less $(p<0.05)$. Antioxidants present in the extract possibly effected the increased scavenging of DPPH radical. Such activity has also been reported in several other plant extracts, including Aframomum corrorima (Braun), ${ }^{44}$ Stevia rebaudiana,${ }^{36}$ Chromolaena odorata ${ }^{45}$ and Agaricus bisporus. ${ }^{37}$

Demonstration of reducing power is based on the principle of increase in the absorbance of reaction mixtures. In this method, an antioxidant compound forms a colored complex with potassium ferricyanide, TCA and $\mathrm{FeCl}_{3}$, which is measured at $700 \mathrm{~nm}$. Increase in the absorbance of the reaction mixture provides a measure of the reducing power of the sample, suggesting its antioxidant potential. ${ }^{46}$ In the present study, the method of $\mathrm{Oyaizu}^{24}$ was adopted to measure $\mathrm{Fe}^{3+}-\mathrm{Fe}^{2+}$ transformation in the presence of $T$. divaricata leaf extract. We observed that the reducing power of the extract of $T$. divaricata and that of the standard, BHT, steadily increased with increase in concentrations (Figure 5); the reducing power of the extract was also found to approximate the reducing capacity of the standard BHT. Duh et al. ${ }^{47}$ reported that the reducing properties of antioxidants are generally associated with the presence of reductones, such as ascorbic acid. Such reductones exert antioxidant activity by breaking the free radical chain by donating hydrogen atoms; ${ }^{48}$ reductones have also been reported to react with certain precursors of peroxide, thus preventing peroxide formation. ${ }^{49}$ Such a mechanism was possibly effected by the antioxidants present in the extract of $T$. divaricata, therein increasing its reducing power. Extracts of other plants, such as those of Aloe vera, ${ }^{50}$ Barleria prionitis, ${ }^{51}$ Caesalpinia crista,${ }^{52}$ and Agaricus bisporus, ${ }^{53}$ have also been reported to exhibit reducing power, suggesting their antioxidant potential.

Transition metals are believed to catalyze the initial formation of radicals. Chelating agents may stabilize transition metals in living systems and inhibit generation of radicals, consequently reducing free radicalinduced damage. The principle of this method is that ferrozine can quantitatively form red-colored complexes with $\mathrm{Fe}^{2+}$. In the presence of chelating agents, the formation of such complexes is disrupted, leading to a decrease in the rate of formation of red-colored complexes. Therefore, measurement of the rate of color reduction allows an estimation of chelating activity of the co-existing chelator. ${ }^{54}$ To better understand how the $T$. divaricata extract inhibited generation of radicals, its chelating activity was evaluated against that of $\mathrm{Fe}^{2+}$. In the current investigation, at a concentration of $10 \mathrm{mg} / \mathrm{ml}$, the extract, as well as the standard EDTA, were found to chelate $68 \%$ and $78 \%$ of ferrous ions, respectively; the chelating effect was found to gradually increase with increasing concentrations (Figure 6). Chua et al. ${ }^{55}$ reported that an ethanolic extract of Cinnamomum osmophloeum chelated $66.4 \%$ of ferrous ions at a concentration of $2.5 \mathrm{mg} / \mathrm{ml}$. A methanolic extract of Black stinkhom, at a concentration of $24 \mathrm{mg} / \mathrm{ml}$, was found to chelate $46.4 \%-52.0 \%$ of ferrous ions $s^{56}$ and an ethanolic extract of Pleurotus citrinopileatus chelated $22.30 \%$ of ferrous ions at $20 \mathrm{mg} / \mathrm{ml} .{ }^{57}$ The results of the present study suggest that an ethanolic extract of $T$. divaricata exhibits good chelating activity on ferrous ions, thereby preventing the generation of free radicals. The observed hydroxyl, superoxide and DPPH-radical scavenging potential, reducing power and metal-chelating activity of the T. divaricata extract were possibly due to the presence of perceptible quantities of antioxidant constituents.

\section{CONCLUSION}

The results of the present study suggest that an ethanolic extract of $T$. divaricata leaves possesses phytoconstituents with antioxidant potential, which is manifested by concentration-dependent scavenging of hydroxyl, superoxide and DPPH free radicals, reducing power and chelating of ferrous ions. The relevance of these results in the context of medicinal use of the extract of $T$. divaricata leaves requires further study.

\section{ACKNOWLEDGEMENTS}

The instrumentation facility provided by the University Grants CommissionSpecial Assistance Program-Departmental Research Support (UGCSAP-DRS-II) of the Department of Animal Science, Bharathidasan University, is acknowledged. The authors are grateful to Jawaharlal Nehru University (JNU), New Delhi for providing instrumentation facility to carry out GC-MS analysis. Financial support rendered by University Grants Commission-Basic Scientific Research (UGC-BSR) to the corresponding author is also gratefully acknowledged.

\section{CONFLICTS OF INTEREST}

The authors declare that there is no conflict of interest. 


\section{ABBREVIATIONS USED}

GC-MS: Gas chromatography mass spectrometry; IC $_{50}$ : Half maximal inhibitory concentration; DPPH: 1, 1-diphenyl-2-picrylhydrazyl; ROS: Reactive oxygen species; SPSS: Statistical Package for Social Sciences.

\section{REFERENCES}

1. Gholivand MB, Rahimi-Nasrabadi M, Batooli $H$, Ebrahimabadi AH. Chemical composition and antioxidant activities of the essential oil and methanol extracts of Psammogeton canescens. Food and Chemical Toxicology. 2010;48(1):24-8.

2. Matkowski A. Plant in vitro culture for the production of antioxidants. Biotechnology Advances. 2008;26(6):548-60.

3. Palmer HJ, Eric Paulson K. Reactive oxygen species and antioxidants in signal transduction and gene expression. Nutrition Reviews. 1997;55(10):353-61.

4. Saito M, Sakagami H, Fujisawa S. Cytotoxicity and apoptosis induction by butylated hydroxyanisole (BHA) and butylated hydroxytoluene (BHT). Anticancer Research. 2003; 23(6C):4693-701.

5. Subhasree B, Baskar R, Laxmi Keerthana R, Lijina Susan R, Rajasekaran P. Evaluation of antioxidant potential in selected green leafy vegetables. Food Chemistry.2009;115(4):1213-20.

6. Djeridane A, Yousfi M, Brunel JM, Stocker P. Isolation and characterization of a new steroid derivative as a powerful antioxidant from Cleome arabica in screening the in vitro antioxidant capacity of 18 Algerian medicinal plants. Food and Chemical Toxicology. 2010;48(10):2599-606.

7. Pourmortazavi SM, Hajimirsadeghi SS. Supercritical fluid extraction in plant essential and volatile oil analysis. Journal of Chromatography A. 2007;1163(1-2): 2-24.

8. Gholivand MB, Rahimi-Nasrabadi M, Chalabi H. Determination of essential oi components of star anise (Illicium verum) using simultaneous hydrodistillationstatic headspace liquid-Phase microextraction-gas chromatography mass spectrometry. Analytical Letters. 2009;42(10):1382-97.

9. Rahimi-Nasrabadi M, Gholivand MB, Batooli H. Chemical composition of the essential oil from leaves and flowering aerial parts of Haplophyllum robustum Bge. (Rutaceae). Digest Journal of Nanomaterials and Biostructures. 2009 4(4):819-22

10. Gachkar L, Yadegari D, Rezaei MB, Taghizadeh M, Astaneh Sh.A, Rasooli I. Chemical and biological characteristics of Cuminum cyminum and Rosmarinus officinalis essential oils. Food Chemistry. 2007;102(3):898-904.

11. Sharififar F, Dehghn-Nudeh Gh, Mirtajaldini M. Major flavonoids with antioxidant activity from Teucrium polium L. Food Chemistry. 2009;112(4):885-8.

12. Chintamunnee V, Mahomoodally MF. Herbal medicine commonly used against infectious diseases in the tropical island of Mauritius. Journal of Herbal Medicine. 2012;2(1):113-25.

13. Gurib-Fakim A. Medicinal plants: traditions of yesterday and drugs of tomorrow Molecular Aspects of Medicine. 2006;27(1):1-93.

14. Nunkoo H, Mahomoodally MF. Ethnopharmacological survey of native remedies commonly used against infectious diseases in the tropical island of Mauritius. Journal of Ethnopharmacology. 2012;143(2):548-64.

15. Jana S, Shekhawat GS. Anethum graveolens: An Indian traditional medicinal herb and spice. Pharmacognosy Reviews. 2010;4(8):179-84.

16. Van Beek TA, Verpoorte $R$, Svendsen AB, Leeuwenberg AJ, Bisset NG Tabernaemontana L. (Apocynaceae): A review of its taxonomy, phytochemistry, ethnobotany and pharmacology. Journal of Ethnopharmacology. 1984;10(1): $1-156$

17. Ingkaninan K, Changwijit K, Suwanborirux K. Vobasinyl-iboga bisindole alkaloids potent acetylcholinesterase inhibitors from Tabernaemontana divaricata root. The Journal of Pharmacy and Pharmacology. 2006;58(6):847-52.

18. PratchayasakulW, Pongchaidecha A, Chattipakorn N, Chattipakkorn S. Ethnobotany and ethnopharmacology of Tabernaemontana divaricata. The Indian Journal of Medical Research. 2008; 127(1):317-35

19. Jain S, Jain A, Jain N, Jain DK, Balekar N. Phytochemical investigation and evaluation of in vitro free radical scavenging activity of Tabernaemontana divaricata Linn. Natural Product Research. 2010;24(3):300-4.

20. Halliwell B, Gutteridge JM, Aruoma OI. The deoxyribose method: A simple "test-tube" assay for determination of rate constants for reactions of hydroxyl radicals. Analytical Biochemistry. 1987;165(1):215-9.

21. Liu F, Ooi VE, Chang ST. Free radical scavenging activities of mushroom polysaccharide extracts. Life Sciences. 1997;60(10):763-71.

22. RajeshwarY, Kumar GS, Gupta M, Mazumder UK. Studies on in vitro antioxidant activities of methanol extract of Mucuna pruriens (Fabaceae) seeds. European Bulletin of Drug Research. 2005;13(1):31-9.

23. Kikuzaki H, Nakatani N. Antioxidant effects of some ginger constituents. Journal of Food Science. 1993;58(6):1407-10.

24. Oyaizu M. Studies on products of browning reaction: Antioxidative activities of products of browning reaction prepared from glucosamine. The Japanese Journal of Nutrition and Dietetics. 1986;44(6):307-15.
25. Dinis TCP, Madeira VM, Almeida LM. Action of phenolic derivatives (Acetaminophen, Salicylate, and 5-Aminosalicylate) as inhibitors of membrane lipid peroxidation and as peroxyl radical scavengers. Archives of Biochemistry and Biophysics. 1994:315(1):161-9

26. Geronikaki A, Hadjipavlou-Litina D, Chatziopoulos C, Soloupis G. Synthesis and biological evaluation of new 4,5-disubstituted-thiazolyl amides, derivatives of 4-hydroxy-piperidine or of 4-N-methyl piperazine. Molecules. 2003;8(6):472-9.

27. Kala MJ, Soris T, Mohan VR. GC-MS determination of bioactive components of Eugenia flocossa bedd. (myrtaceae). International Journal of Pharma and Bio Sciences. 2012;3(1):277-82.

28. Kumar PP, Kumaravel S, Lalitha C. Screening of antioxidant activity, total phenolics and GC-MS study of Vitex negundo. African Journal of Biochemistry Research. 2010;4(7):191-5

29. Santos CC, Salvadori MS, Mota VG, Costa LM, de Almeida AA, de Oliveira GA, Costa JP, de Sousa DP, de Freitas RM, de Almeida RN. Antinociceptive and antioxidant activities of phytol in vivo and in vitro models. Neuroscience Journal. 2013: 949452. doi: 10.1155/2013/949452.

30. Gopalakrishnan S, Vadivel E. GC-MS Analysis of some bioactive constituents of Mussaenda frondosa Linn. International Journal of Pharma and Bio Sciences. 2011:2(1):313-20

31. Mujeeb F, Bajpai P, Pathak N. Phytochemical evaluation, antimicrobial activity, and determination of bioactive components from leaves of Aegle marmelos. Biomed Reseaech International. 2014;497606. doi: 10.1155/2014/497606.

32. Naga Vamsi Krishna A, Venkata Raman B, Ramesh Babu K, Apparao C. Antioxidant activity and GC-MS analysis of Phragmytes vallatoria leaf ethanolic extract. International Research Journal of Pharmacy. 2012;3(3):252-4

33. Thangam R, Suresh V, Rajkumar M, Vincent JD, Gunasekaran P, Anbazhagan C, Kaveri K, Kannan S. Antioxidant and in vitro anticancer effect of 2-Pyrrolidinone rich fraction of Brassica oleracea var. capitata through induction of apoptosis in human cancer cells. Phytotherapy Research. 2013;27(11):1664-70.

34. Das NP. Effects of Vitamin A and its analogs on nonenzymatic lipid peroxidation in rat brain mitochondria. Journal of Neurochemistry. 1989;52(2):585-8.

35. Duan X, Wu G, Jiang Y. Evaluation of the antioxidant properties of Litchi fruit phenolics in relation to pericarp browning prevention. Molecules. 2007;12(4): 759-71.

36. Shukla S, Mehta A, Bajpai VK, Shukla S. In vitro antioxidant activity and total phenolic content of ethanolic leaf extract of Stevia rebaudiana Bert. Food and Chemical Toxicology. 2009a;47(9):2338-43.

37. Liu J, Jia L, Kan J, Jin C-h. In vitro and in vivo antioxidant activity of ethanolic extract of white button mushroom (Agaricus bisporus). Food and Chemical Toxicology. 2013;51:310-16.

38. Stamenic M, Vulic J, Djilas S, Misic D, Tadic V, Petrovic S, Zizovic I. Free-radica scavenging activity and antibacterial impact of Greek oregano isolates obtained by SFE. Food Chemistry. 2014;165:307-15

39. Halliwell B, Gutteridge JM. Free Radicals, Ageing and Disease. Free Radiclas in Biology and Medicine. 2nd Edn. Oxford: Clarendon Press, New York. 1985; pp. 279-315.

40. Beauchamp C, Fridovich I. Superoxide dismutase: Improved assays and an assay applicable to acrylamide gels. Analytical Biochemistry. 1971;44(1):276-87.

41. Shukla S, Mehta A, John J, Singh S, Mehta P, Vyas SP. Antioxidant activity and total phenolic content of ethanolic extract of Caesalpinia bonducella seeds. Food and Chemical Toxicology. 2009;47(8):1848-51.

42. Soare JR, Dinis TC, Cunha AP, Almeida LM. Antioxidant activities of some extracts of Thymus zygis. Free Radical Research. 1997;26(5):469-78

43. Brand-Williams W, Cuvelier ME, Berset C. Use of a free radical method to evaluate antioxidant activity. LWT - Food Science and Technology. 1995;28(1):25-30.

44. Eyob S, Martisen BK, Tsegaye A, Appelgren M, Skrede G. Antioxidant and antimicrobial activities of extract and essential oil of korarima (Aframomum corrorima (Braun) P.C.M. Jansen). African Journal of Biotechnology. 2008;7(15):2585-92.

45. Srinivasa Rao K, Chaudhury PK, Pradhan A. Evaluation of anti-oxidant activities and total phenolic content of Chromolaena odorata. Food and Chemical Toxicology 2010;48(2):729-32.

46. Jayaprakasha GK, Singh RP, Sakariah KK. Antioxidant activity of grape seed (Vitis vinifera) extracts on peroxidation models in vitro. Food Chemistry. 2001;73(3):285-90.

47. Duh PD, Tu YY, Yen GC. Antioxidant activity of water extract of Harng Jyur (Chrysanthemum morifolium Ramat). LWT - Food Science and Technology. 1999;32(5):269-77.

48. Gordon $\mathrm{MH}$. The mechanism of antioxidant action in vitro. In: Hudson BJF (ed) Food Antioxidants. Elsevier Applied Food Science Series. Springer. 1990 pp. 1-18.

49. Xing R, Liu S, Guo Z, Yu H, Wang P, Li C, Li Z, Li P. Relevance of molecular weight of chitosan and its derivatives and their antioxidant activities in vitro. Bioorganic and Medicinal Chemistry. 2005;13(5):1573-7.

50. Miladi S, Damek M. In vitro antioxidant activities of Aloe vera leaf skin extracts. Journal de la Société Chimique de Tunisie. 2008;10:101-9.

51. Jaiswal SK, Dubey MK, Das S, Verma AR, Rao CV. A comparative study on total phenolic content, reducing power and free radical scavenging activity of aerial parts of Barleria prionitis. International Journal of Phytomedicine. 2010;2(2):155-9. 
52. Mandal S, Hazra B, Sarkar R, Biswas S, Mandal N. Assessment of the antioxidant and reactive oxygen species scavenging activity of methanolic extract of Caesalpinia crista leaf. Evidence Based Complementary and Alternative Medicine. 2011; 173768. doi:10.1093/ecam/nep072.

53. Reis FS, Martins A, Barros L, Ferreira IC. Antioxidant properties and phenolic profile of the most widely appreciated cultivated mushrooms: A comparative study between in vivo and in vitro samples. Food and Chemical Toxicology. 2012;50(5):1201-7.

54. Yamaguchi F, Ariga T, Yoshimura Y, Nakazawa H. Antioxidative and anti-glycation activity of Garcinol from Garcinia indica fruit rind. Journal of Agricultural and Food Chemistry. 2000;48(2):180-5.

55. Chua MT, Tung YT, Chang ST. Antioxidant activities of ethanolic extracts from the twigs of Cinnamomum osmophloeum. Bioresource Technology.
2008;99(6):1918-25

56. Linn HC. Evaluation of taste quality and antioxidant properties of edible and medicinal mushrooms. Master's Thesis. National Chung-Hsing University, Taichung, Taiwan. 1999.

57. Lee YL, Huang GW, Liang ZC, Mau, JL. Antioxidant properties of three extracts from Pleurotus citrinopileatus. LWT - Food Science and Technology. 2007;40(5):823-33.

58. Manorenjitha MS, Norita AK, Norhisham S, Asmawi MZ. GC-MS analysis of bioactive components of Ficus religiosa (Linn.) stem. International Journal of Pharma and Bio Sciences. 2013;4(2):99-103.

59. Selvamangai G, Bhaskar A. GC-MS analysis of phytocomponents in the methanolic extract of Eupatorium triplinerve. Asian Pacific Journal of Tropical Biomedicine. 2012:2(3):S1329-S1332.

\section{PICTORIAL ABSTRACT}

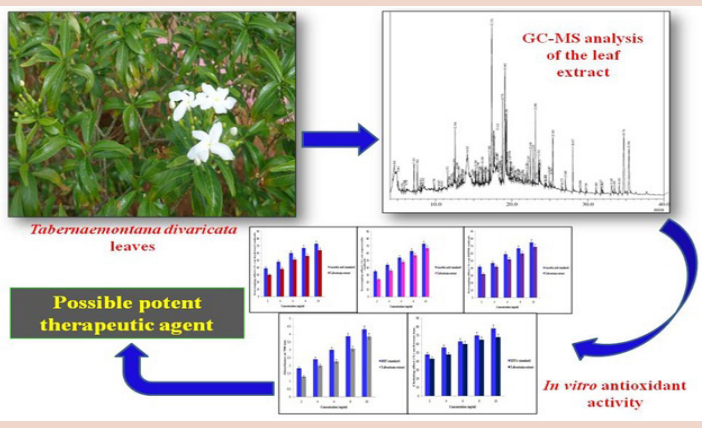

\section{SUMMARY}

- The current study sought to identify bioactive constituents present in the leaf ethanolic extract of $T$. divaricata using gas chromatography-mass spectrometry analysis and to elucidate various antioxidant characteristics.

- The possible presence of antioxidant constituents in the extract of $T$. divaricata was responsible for the observed hydroxyl, superoxide and DPPH-radical scavenging potential, reducing power and metal-chelating activity.

- $\quad$ The results suggest that the leaf ethanolic extract of $T$. divaricata could act as a possible therapeutic agent for oxidative stress-induced pathological states. 